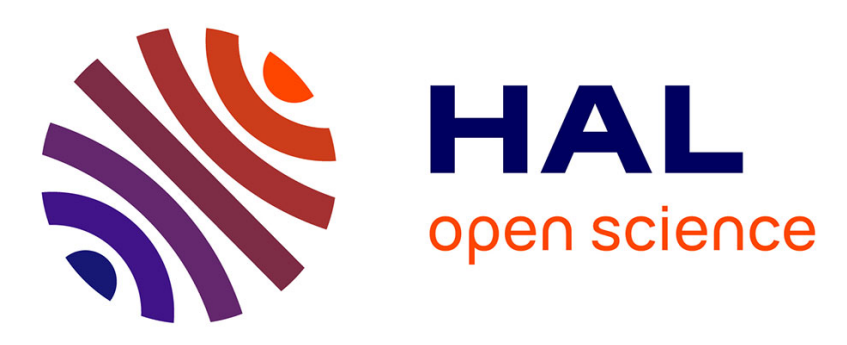

\title{
Models of Tet-On System with Epigenetic Effects
}

Russ Harmer, Jean Krivine, Élise Laruelle, Cédric Lhoussaine, Guillaume

Madelaine, Mirabelle Nebut

\section{To cite this version:}

Russ Harmer, Jean Krivine, Élise Laruelle, Cédric Lhoussaine, Guillaume Madelaine, et al.. Models of Tet-On System with Epigenetic Effects. Computational Methods in Systems Biology 2012 (CMSB 2012, Flashposter), Oct 2012, London, United Kingdom. pp.378. hal-00725553

\section{HAL Id: hal-00725553 https://hal.science/hal-00725553}

Submitted on 27 Aug 2012

HAL is a multi-disciplinary open access archive for the deposit and dissemination of scientific research documents, whether they are published or not. The documents may come from teaching and research institutions in France or abroad, or from public or private research centers.
L'archive ouverte pluridisciplinaire HAL, est destinée au dépôt et à la diffusion de documents scientifiques de niveau recherche, publiés ou non, émanant des établissements d'enseignement et de recherche français ou étrangers, des laboratoires publics ou privés. 


\title{
Models of Tet-On System with Epigenetic Effects
}

\author{
Russ Harmer ${ }^{1}$, Jean Krivine ${ }^{1}$, Élise Laruelle ${ }^{1}$, Cédric Lhoussaine ${ }^{2}$, Guillaume \\ Madelaine $^{2,3}$, Mirabelle Nebut ${ }^{2}$ \\ 1 PPS (CNRs Umr 7126), University Paris Diderot, France \\ 2 LifL (CNRS UMr 8022), University of Lille 1, France \\ 3 Éns Cachan, France
}

\begin{abstract}
We present the first results of ongoing work investigating two models of the artificial inducible promoter Tet-On that include epigenetic regulation. We consider chromatin states and 1D diffusion of transcription factors that reveal, respectively, stochastic noise and a memory effect.
\end{abstract}

\section{Introduction}

In gene regulatory systems, transcription factors (TF) usually require activation in order to perform their regulatory function. This generally results from the action of complex signalling pathways, so an investigation of the dynamics of $\mathrm{TF}$ activation is important for understanding the underlying gene regulation. Recently, an efficient experimental technique to monitor this dynamics has been proposed, using fluorescent proteins expressed under the control of an inducible promoter by the $\mathrm{TF}$ of interest. However, observed fluorescence is not linearly correlated to the TF activation: a delay is induced by fluorescent protein expression and subsequent folding; and fluorescence may persist even after TF deactivation. Huang et al [4] propose a method to reconstruct TF dynamics from observed fluorescent protein dynamics by means of a very simple two-level model of the Tet-On system, an artificial inducible promoter of Green Fluorescent Protein (GFP). The first level (rules (1) to (3) below) models the signal transduction pathway leading to TF activation: this involves the artificial TF $r t T A$, activated by binding with doxycycline $D o x_{i}$. Extracellular doxycycline $D o x_{e}$ is assumed constant and can degrade in the cell. The second level (rules (4) to (9)) models protein synthesis and activation of fluorescence: this includes transcription, translation and GFP activation.

$$
\begin{aligned}
& D_{0 x} \stackrel{\text { Deff }}{\longrightarrow} D_{0} x_{e}+D_{o x} \\
& D o x_{i} \stackrel{\text { Deff }}{\longrightarrow} \emptyset \\
& r t T A+D o x_{i} \underset{k_{r 2}}{\stackrel{k_{f 2}}{\rightleftharpoons}} r t T A \cdot D o x \\
& r t T A \cdot D o x \stackrel{S_{m}^{\prime}}{\longrightarrow} r t T A \cdot D o x+m R N A \\
& m R N A \stackrel{D_{m}}{\longrightarrow} \emptyset \\
& m R N A \stackrel{S_{n}}{\longrightarrow} G F P+m R N A \\
& G F P \stackrel{S_{f}}{\longrightarrow} G F P a \\
& G F P \stackrel{D_{n}}{\longrightarrow} \emptyset \\
& G F P_{a} \stackrel{D_{n}}{\longrightarrow} \emptyset
\end{aligned}
$$



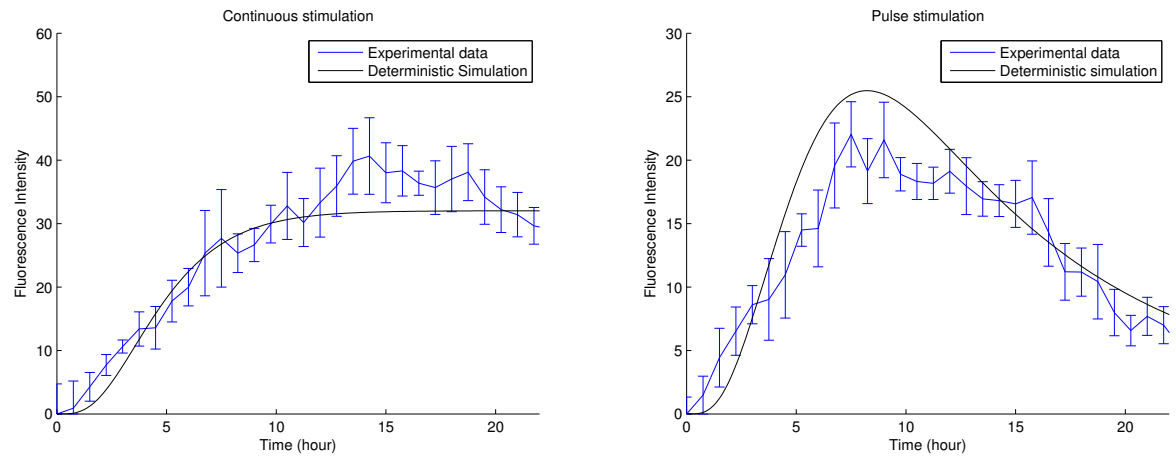

Fig. 1. Continuous (left) and pulse (right) stimulation with doxycycline.

Fig. 1 shows that the dynamics predicted by the deterministic model is in good agreement with experimental data in the case of continuous and pulse ${ }^{4}$ stimulation with doxycycline. In [4], the authors demonstrate that the dynamics of TF activation is accurately correlated with the dynamics offluorescence.

In this paper, we propose two simple extensions of the basic model proposed in [4] to investigate effects that may result from epigenetic regulation. The first extension deals with chromatin states, i.e. the (un)availability of the inducible promoter due to chromatin compaction. In the second, we model TF diffusion along DNA, i.e. the binding of a TF to non-specific binding sites, followed by its sliding to the operator site.

\section{Chromatin states: a stochastic noise effect}

The experimental data of [4] appear to be quite noisy, contrary to what is predicted by the original model (Fig. 2 left). Although it is hard to assess quantitatively, we can assume that some of this noise results from intrinsic stochasticity. A recognized likely source of stochasticity in gene regulation is the dynamic alteration of chromatin structure that makes it more or less accessible to the transcriptional machinery. Most of the time, the chromatin is tightly packaged or, roughly speaking, in a closed state. This implies that the TF cannot find the promoter to activate transcription; to allow rtTA . Dox to bind with the promoter, the chromatin must be in an open state. Depending on the needs of the cell, the chromatin can rapidly switch between these states.

We refine the model given in the introduction by replacing reaction (4) with reactions (10) to (13) below. In words, $r t T A \cdot D o x$ can bind its operator site (rule (10)) when the chromatin is locally open; then, either $r t T A \cdot D o x$ can dissociate from the operator (rule (10)), or transcription can begin (rule (13)). At any time, the chromatin can switch to a closed state (rule (11)); if the TF is bound to the operator when the chromatin closes, then it dissociates (rule (12)).

\footnotetext{
${ }^{4}$ this means that $D o x_{e}$ concentration is set to zero after some delay.
} 

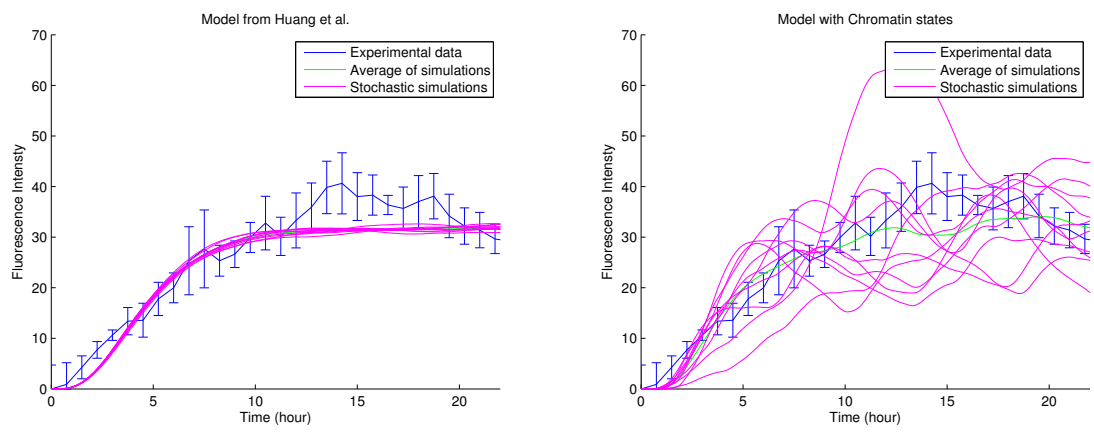

Fig. 2. Comparison of the stochastic noise between the basic model (left) and the model with chromatin states (right).

We take values for $k_{\text {rop }}$ and $k_{f o p}$ of the same order as those for Tet $R$ given in [1]. The values of $k_{\text {closed }}$ and $k_{\text {open }}$ are actually dependent on the promoter used, the position of the gene, the cell type, etc, but the values taken here are close to those of promoters found in mammalian cells [6]. Finally, the rate constant of transcription (rule (13)) has been chosen to fit the experimental data.

$$
\begin{aligned}
& r t T A \cdot D o x+O p_{\text {open }} \stackrel{k_{\text {fop }}}{\underset{k_{\text {rop }}}{\rightleftharpoons}} O p_{\text {open }} \cdot r t T A \cdot \text { Dox } \\
& O p_{\text {closed }} \stackrel{\stackrel{k_{\text {open }}}{\rightleftharpoons} O p_{\text {closed }}}{\longrightarrow} O p_{\text {open }} \\
& O p_{\text {open }} \cdot r t T A \cdot D o x \stackrel{k_{\text {closed }}}{\longrightarrow} O p_{\text {closed }}+r t T A \cdot D o x \\
& O p_{\text {open }} \cdot r t T A \cdot D o x \stackrel{k_{\text {trans }}}{\longrightarrow} O p_{\text {open }} \cdot r t T A \cdot D o x+m R N A
\end{aligned}
$$

The average of the stochastic simulations in Fig. 2 is close to the deterministic dynamics given by Huang et al. [4], as expected, but stochastic noise is far more pronounced than in the basic model. The influence of chromatin states could thus provide an explanation for the noise observed in the experimental data.

\section{1D diffusion of TF: a memory effect}

Another interesting aspect of gene regulation is related to how the TF finds its promoter since it is known that three-dimensional (3D) diffusion is insufficient to explain fast binding [5]. In [3], a diffusion-based model is proposed: once the TF has (3D-) diffused within the nucleus and bound randomly to a non-specific DNA site, it rapidly slides along the DNA (1D diffusion) in a small region. If there is an operator in this region, it has an approximately 50-50 chance to bind it. In the case of binding, transcription can begin; otherwise, the TF either unbinds completely, returning to a search by $3 \mathrm{D}$ diffusion, or it jumps to another non-specific binding site in a neighbouring area.

We add this behaviour to the basic model with 14 new reactions (due to lack of space, we don't report them here). The transcription rate has again 

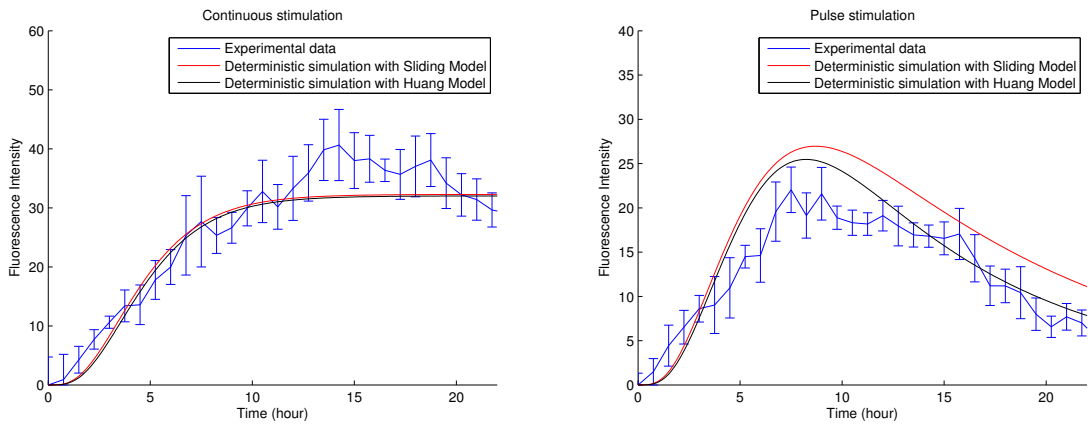

Fig. 3. Comparison between Huang model and Sliding model, with a continuous (left) or pulse (right) stimulation of doxycycline.

been chosen to fit the experimental data and the other parameters have been taken from [3] and [2]. The results of the deterministic simulations in Fig. 3 are interesting: there is no significant difference in the case of constant stimulation but, in the pulse case, fluorescence decays more slowly than in the basic model which can be interpreted as a sort of "memory effect".

\section{Conclusion}

We have developed two extensions of the Tet-On model of [4]. The first, adding chromatin states, increases stochastic noise but preserves the average behaviour in accordance with the experimental data. The second, adding a search for the operator by the TF via 1D diffusion, reveals a delayed decay in fluorescence after stimulation has ceased. We are currently investigating this effect in more detail, notably in the case where there are multiple operator sites in close proximity.

\section{References}

1. K. Biliouris, P. Daoutidis, and Y. N. Kaznessis. Stochastic simulations of the tetracycline operon. BMC systems biology, 5, 2011.

2. I. Bonnet. Mécanismes de diffusion facilitée de l'enzyme de restriction EcoRV. 2007.

3. P. Hammar, P. Leroy, A. Mahmutovic, E. G. Marklund, O. G. Berg, and J. Elf. The lac repressor displays facilitated diffusion in living cells. Science, 336(6088):15951598, June 2012.

4. Z. Huang, C. Moya, A. Jayaraman, and J. Hahn. Using the Tet-On system to develop a procedure for extracting transcription factor activation dynamics. Molecular bioSystems, 6(10):1883-1889, October 2010.

5. A. D. Riggs, S. Bourgeois, and M. Cohn. The lac repressor-operator interaction. 3. kinetic studies. Journal of molecular biology, 53(3):401-417, November 1970.

6. D. M. Suter, N. Molina, D. Gatfield, K. Schneider, U. Schibler, and F. Naef. Mammalian genes are transcribed with widely different bursting kinetics. Science, 332(6028):472-474, April 2011. 